\title{
O Programa Novas Oportunidades numa agenda globalmente estruturada para a educação
}

\author{
Marcelo Marques*
}

Natália Alves*

\begin{abstract}
Resumo
Este artigo apresenta uma análise crítica da criação e implementação da mais emblemática medida política para o campo de jovens e adultos pouco escolarizados em Portugal: o Programa Novas Oportunidades. Recorrendo à proposta de Roger Dale sobre a agenda globalmente estruturada para a educação, discutiu-se a fabricação desta medida a partir de um cenário de regulação transnacional. Através da análise documental de um conjunto de documentos europeus e nacionais entre o período de 2000 e 2010 para o campo da educação de jovens e adultos, verificou-se que o Programa Novas Oportunidades é consequência de um fortalecimento do processo de regulação das políticas educativas, levado a cabo pela União Europeia. Este fortalecimento resultou na construção de um programa político para o campo da educação de jovens e adultos em Portugal que comunga náo só das mesmas ideologias instrumentais para a educação da União Europeia, como de uma gestão tecnocrática das políticas educativas, assente na procura de resultados.
\end{abstract}

Palavras-chave: Meio Político. Política Mundial da Educação. Educação de Jovens e Adultos.

*Doutorando do Instituto de Educação da Universidade de Lisboa.

** Doutora em Educação pela Universidade de Lisboa. Professora auxiliar do Instituto de Educação da Universidade de Lisboa. 


\section{Introdução}

O Programa Novas Oportunidades (PNO), lançado em 2005, apresenta-se como uma das políticas para jovens e adultos pouco escolarizados com maior visibilidade em Portugal. Este programa é legitimado por um (in) questionável discurso, ancorado nos desígnios da Teoria do Capital Humano:

O desenvolvimento do país confronta-nos com uma opção clara e inadiável: a aposta na qualificação da população portuguesa. [e/ou] A importância central da qualificação para o crescimento económico e para a promoção da coesão social está hoje amplamente demonstrada por diversos indicadores publicados por várias organizaçôes internacionais. (SÓCRATES, 2005, p. 2).

O PNO procura assim, atingir duas grandes finalidades: fazer do $12^{\circ}$ ano o referencial mínimo de qualificação para a população em geral, e em particular para os jovens, e qualificar um milhão de ativos até 2010, através do Sistema de Reconhecimento, Validação e Certificação de Competências e dos cursos de Educação e Formação de Adultos. Este Programa surge enquadrado num plano nacional desdobrado em dois momentos temporais - entre 2005-2008, no Plano Nacional para o Crescimento e o Emprego (PNACE); e entre 2008-2010, no Plano Nacional de Reformas.

Esses planos nacionais são expressão de uma ambição que se projeta além das fronteiras nacionais, e se apresenta como parte integrante de um programa supranacional, dirigido pela União Europeia (UE), integrado no seu programa de ação designado por Estratégia de Lisboa, e que visa tornar a economia europeia na mais competitiva do mundo.

O presente texto procura compreender a influência dessa entidade supranacional na construção do PNO, num cenário de regulação transnacional. Assim, a primeira parte do texto procura apresentar a abordagem em que nos afiliamos - a agenda globalmente estruturada para a educação - para depois dar conta da metodologia utilizada. Por fim, apresentamos os principais resultados da nossa investigação e consequentes consideraçóes finais. 


\section{Agenda Globalmente Estruturada para a Educação: os imperativos económicos na pilotagem da educação global}

O estudo do Programa Novas Oportunidades, enquanto política pública para o campo de jovens e adultos pouco escolarizados, obriga a dotarmo-nos de um olhar caleidoscópico para entendermos o objeto de estudo num cenário em que a fabricação de políticas públicas se apresenta como um processo instável, interacional e contínuo.

A agenda globalmente estruturada para a educação (DALE 1999, 2001, 2002), permite-nos compreender a noção de política enquanto processo, ao enfatizar que as políticas para a educaçáo se constroem, na atualidade, a partir de um trabalho pluriescalar (DALE, 2005), em que se jogam diversas forças entre organizaçôes internacionais, instâncias regionais, como a União Europeia, e Estados nacionais. Estas forças são devedoras da intensificação dos processos de globalização que, para a presente abordagem, se traduz no triunfo do capitalismo como único e exclusivo modelo económico em vigor. Mais do que um conjunto de valores e transformaçóes culturais e sociais, a proposta do autor entende a globalizaçáo como um fenómeno económico-político. Para a perpetuação do sistema capitalista, os Estados nacionais obedecem a um conjunto de pressôes e regulaçóes globais, delegando competências em órgãos supranacionais, por um lado, e alterando os seus modos de atuação, por outro. Um dos conceitos fundamentais é o de escala, que nos permite localizar onde os fenómenos acontecem, o que possibilita compreender que a atividade social é organizada especialmente e é produzida racionalmente (DALE; ROBERTSON, 2007). Por sua vez, outro conceito fundamental nessa abordagem é o conceito de governação (transnacional), que permite conhecer quem produz essas mudanças e de que forma essa produçáo é regulada (DALE; ROBERTSON, 2007).

Para essa proposta, as alteraçóes nos sistemas educativos são sinónimo de uma mudança no mandato da educaçáo, alterando o seu propósito, na medida em que se assiste a uma passagem de um sistema que procurava a justiça social, para um outro que suporta o regime de acumulação de capital, fazendo com que as políticas educativas nacionais estejam subordinadas aos imperativos económicos da agenda global.

Admitindo que uma das principais caraterísticas das relaçóes internacionais consiste numa coordenação das atividades políticas, cristalizada na expressão 
governação sem governo (DALE, 2002; 2005), o conceito de regulação surge como um elemento chave de análise, permitindo compreender a complexidade das relaçóes entre a União Europeia e o Estado português, na implementação do Programa Novas Oportunidades.

Para a compreensão desses fenómenos é necessária uma análise profunda quanto aos modos de governação na educação, identificando, de igual modo, as escalas onde os fenómenos acontecem. Apesar da existência de uma agenda global a seguir, que em última análise pode levar a processos de convergência, esta náo inibe a contínua divergência na implementação da agenda nos diversos Estados nacionais (DALE; ROBERTSON, 2002).

Para esse propósito, torna-se imperativo mobilizar o conceito de regulação desenvolvido por João Barroso (2006a, p. 12), entendido como "[...] os modos como são produzidas e aplicadas as regras que orientam a acção dos actores [...] e os modos como esses mesmos actores se apropriam delas". Para entender os níveis de atuação dessas regras, o autor define dois níveis distintos de análise. Assim, Barroso (2006b) distingue regulação transnacional de regulação nacional. Por regulação transnacional entende-se:

[...] conjunto de normas, discursos e instrumentos que são produzidos e circulam nos fóruns de decisão e consulta internacionais, no domínio da educação, que são tomados pelos políticos, funcionários ou especialistas nacionais, como "obrigação" e "legitimação" para adoptarem ou proporem decisóes ao nível do funcionamento do sistema educativo. (BARROSO, 2006b, p. 44-45).

Por sua vez, por regulação nacional entende-se: “[...] o modo como as autoridades públicas exercem a coordenação, o controlo e a influência sobre o sistema educativo, orientando através de normas, injunçóes e constrangimentos o contexto da acção dos diferentes actores sociais e seus resultados" (BARROSO, 2006b, p. 50).

Sendo o nosso objecto de estudo a criação e implementação do Programa Novas Oportunidades, a abordagem apresentada e a distinção entre regulação transnacional e nacional, apresentam-se como ferramentas concetuais fundamentais para analisar e compreender a relação estabelecida e desenvolvida entre a União Europeia e Portugal, na passada década. 


\section{Construir um dispositivo metodológico para desconstruir ideologias}

Para compreender a fabricação do Programa Novas Oportunidades no quadro da agenda globalmente estruturada para a educação e dos processos de regulação transnacional, reunimos um conjunto de documentos produzidos entre 2000 e 2010, período que corresponde à ratificação da Estratégia de Lisboa e à criação e implementação do Programa Novas Oportunidades. Para analisar a ação da União Europeia nos baseamos nas Conclusóes da Presidência, no Programa Educação e Formação 2010, e respetivos relatórios de progresso, nos documentos elaborados pelos Grupos de Trabalho da Comissão e nas recomendações do Conselho Europeu. Por sua vez, para o Estado Português, contemplámos o Programa Nacional de Ação para o Crescimento e o Emprego (2005-2008), o Plano Nacional de Reformas (2008-2010), os respetivos relatórios de progresso, assim como a legislaçáo e outros documentos que se mostraram pertinentes.

Os documentos selecionados foram, posteriormente, objeto de uma análise qualitativa do discurso (ALTHEIDE, 2008), com recurso à análise crítica do discurso (FAIRCLOUGH, 1995). A opção por essas técnicas decorre do fato de elas serem as que melhor permitem identificar os significados, as ideologias e os discursos veiculados pelos documentos oficiais, os quais induzem e condicionam a açáo dos sujeitos.

$\mathrm{Na}$ ótica de Altheide et al. (2008), o investigador deve explorar interativamente um conjunto inicial de documentos, para em seguida os contextualizar em determinadas ideias e conceitos, que resultam na desconstrução de representaçóes simbólicas da realidade. $\mathrm{Na}$ mesma linha de pensamento, Fairclough (1995) afirma que as instituiçóes sociais contêm diversas formaçôes ideológicas do discurso, sendo geralmente, uma delas a dominante, simbolizando a norma ideológica. Assim, o discurso e as ações são construídos a partir das normas dessas formaçóes ideológicas, cuja caraterística dominante é a capacidade para naturalizar ideologias, tornando-as como senso comum. Este, ao estar envolto numa opacidade do discurso, é apenas detetável através de uma análise descritiva das produções discursivas.

Para analisar o corpus documental, procedeu-se à construção de quatro categorias: regras de reconhecimento, regras de realização, instrumentos e medidas de referência e função da educação. As duas primeiras categorias apresentam- 
se como instrumentos fundamentais para desconstruir as ideologias e compreender o seu alcance na construção de políticas públicas para o campo de jovens e adultos pouco escolarizados, pois, segundo Bernstein (1996, p. 32 ), "as regras de reconhecimento regulam que significados são relevantes e as regras de realização regulam como os significados são postos em conjunto". A categoria instrumentos e medidas de referência permite-nos analisar o processo de operacionalização dos mecanismos de regulação transnacional; a função da educação possibilita, por seu turno, identificar a conceção de educação veiculada nos documentos.

\section{0 - 2005: da relação tripartida dos processos na educação e formação para criação do Espaço Europeu da Educação à construção do Programa Novas Oportunidades}

Em 2000, é celebrada a ratificação da Estratégia de Lisboa, com um novo objectivo estratégico para a Uniáo Europeia: “[...] tornar-se no espaço económico mais dinâmico e competitivo do mundo baseado no conhecimento e capaz de garantir um crescimento económico e sustentável, com mais e melhores empregos, e com maior coesão social" (CONSELHO EUROPEU, 2000, p. 2).

Para o efeito, entre 2000 e 2003, são lançadas as primeiras regras do jogo que reclamam a urgência de uma Política Educativa Europeia, na tentativa de construir aquilo a que a União Europeia designa por Espaço Europeu de Educação. Assim, esse período é marcado pela articulação, nem sempre harmoniosa, entre os objetivos e marcas de referência da Estratégia de Lisboa, do Processo de Copenhaga e do Programa Educação e Formação 2010.

No Conselho Europeu de Bruxelas de 2003, são finalmente definidas as marcas de referência e os indicadores para o Programa Educação e Formação 2010, sendo o ano marcado pela constituiçáo normativa e formal de um conjunto de orientaçóes para os Estados-membros. Sendo o nosso objectivo compreender a influência desses processos na criação e implementação do Programa Novas Oportunidades, apresentamos no Quadro 1 as marcas de referência e os indicadores que o Programa Educação e Formação 2010 deve cumprir, a fim de tornar a Europa a economia mais competitiva do mundo. 
Quadro 1 - Marcas de referência, objetivos estratégicos e indicadores do Programa Educação e Formação 2010 que estão associados ao Programa Novas Oportunidades

\begin{tabular}{|c|c|c|c|}
\hline & \multirow{2}{*}{$\begin{array}{l}\text { Marcas de } \\
\text { Referência }\end{array}$} & \multicolumn{2}{|c|}{$\begin{array}{c}\text { Objetivos e Indicadores do Programa } \\
\text { Educação e Formação } 2010 \\
\end{array}$} \\
\hline & & $\begin{array}{c}\text { Objetivos } \\
\text { Estratégicos }\end{array}$ & Indicadores \\
\hline \multirow{2}{*}{ Jovens } & $\begin{array}{l}\text { Até } 2010, \text { pelo } \\
\text { menos } 85 \% \text { de } \\
\text { pessoas com } \\
22 \text { anos de } \\
\text { idade devem ter } \\
\text { completado o } \\
\text { Ensino Secundário } \\
\text { na União Europeia } \\
\end{array}$ & $\begin{array}{l}\text { 1.Melhorar a } \\
\text { qualidade e } \\
\text { eficácia dos } \\
\text { sistemas da } \\
\text { educação e } \\
\text { formação }\end{array}$ & $\begin{array}{l}\text { Indicador } \mathrm{n}^{\circ} 4- \\
\text { Completar o Ensino } \\
\text { Secundário } \\
\text { - Percentagem de } \\
\text { pessoas com } 22 \text { anos que } \\
\text { completaram pelo menos } \\
\text { o Ensino Secundário }\end{array}$ \\
\hline & $\begin{array}{l}\text { Até } 2010, \text { deve } \\
\text { ser alcançada } \\
\text { uma taxa média } \\
\text { europeia não } \\
\text { superior a } 10 \% \text { de } \\
\text { abandono escolar } \\
\text { precoce }\end{array}$ & $\begin{array}{l}\text { 2. Facilitar o } \\
\text { acesso a todos } \\
\text { nos sistemas } \\
\text { de educação e } \\
\text { formação }\end{array}$ & $\begin{array}{l}\text { Indicador } \mathrm{n}^{\circ} 23- \\
\text { Abandono Escolar } \\
\text { Precoce - Percentagem da } \\
\text { população entre os } 18 \mathrm{e} \\
24 \text { com o Ensino Básico } \\
\text { e que não se encontra nos } \\
\text { sistemas de educação e } \\
\text { formação }\end{array}$ \\
\hline \multirow[t]{2}{*}{ Adultos } & $\begin{array}{l}\text { Até } 2010, \text { pelo } \\
\text { menos } 85 \% \text { de } \\
\text { pessoas com } \\
22 \text { anos de } \\
\text { idade devem ter } \\
\text { completado o } \\
\text { Ensino Secundário } \\
\text { na União Europeia }\end{array}$ & $\begin{array}{l}\text { 1.Melhorar a } \\
\text { qualidade e } \\
\text { eficácia dos } \\
\text { sistemas da } \\
\text { educação e } \\
\text { formação }\end{array}$ & $\begin{array}{l}\text { Indicador } n^{\circ} 9- \\
\text { Participação em educação } \\
\text { e formação inicial para } \\
\text { pessoas pouco qualificadas } \\
\text { - Percentagem de adultos } \\
\text { com menos do que o } \\
\text { Ensino Secundário que } \\
\text { participaram em qualquer } \\
\text { estrutura de educação e } \\
\text { formação nas últimas } 4 \\
\text { semanas por grupo de idade } \\
(25-34 ; 35-54 \text { e 55-64) }\end{array}$ \\
\hline & $\begin{array}{l}\text { Até } 2010 \text {, o nível } \\
\text { de participação em } \\
\text { aprendizagem ao } \\
\text { longo da vida deve } \\
\text { ser pelo menos } \\
\text { de } 12,5 \% \text { na } \\
\text { população adulta } \\
\text { ativa (grupo etário } \\
\text { 25-64) }\end{array}$ & $\begin{array}{l}\text { 2. Facilitar o } \\
\text { acesso a todos } \\
\text { nos sistemas } \\
\text { de educação e } \\
\text { formação }\end{array}$ & $\begin{array}{l}\text { Indicador } n^{\circ} 19 \\
\text { - Participação na } \\
\text { aprendizagem ao longo } \\
\text { da vida } \\
\text { - Percentagem da } \\
\text { população entre } 25-64 \\
\text { anos com menos do que } \\
\text { o Ensino Secundário, que } \\
\text { participaram em educação } \\
\text { e formação, nas } 4 \text { semanas } \\
\text { anteriores ao questionário }\end{array}$ \\
\hline
\end{tabular}

Fonte: Criado a partir de COMMISSION OF THE EUROPEAN COMMUNITIES, 2003. 
Esse programa marca um novo ciclo na construção da política educativa europeia, assinalando perentoriamente a maturação do processo de europeização para a educação, ao tentar criar padrões educativos europeus a serem seguidos pelos Estados-membros. Como forma de superar o problema do consenso e da regulação em matéria de educação entre os Estados-membros, a União Europeia criou um mecanismo que "facilita a aprendizagem política numa perspetiva de baixo para cima e fortalece a dimensão social da União Europeia através de uma troca constante de informação, deliberação, avaliação das políticas e o 'nomear e envergonhar' entre os Estados-membros" (BÜCHS, 2008, p. 765).

Uma das caraterísticas mais importantes traduz-se na ideia de que não existe, de facto, uma construçáo directa de políticas educativas para os Estados-membros, mas antes orientaçóes, prioridades e objetivos que têm um sentido claramente político. A criação de um sistema de monitorização como o Método Aberto de Coordenaçáo (MAC) coloca-nos perante uma forma de regulação transnacional, legitimando a ação directa dos Estados-membros nos sistemas educativos, perante um padrão europeu. Apesar da União Europeia o definir como um método apolítico ou despolitizado, na verdade, a escolha de padróes de referência e de indicadores que definem áreas prioritárias de intervenção, conferem ao MAC um caráter fortemente político (RADAELLI, 2003). O MAC apresenta-se, entáo, como um instrumento sofisticado de governaçáo supranacional que, para Dale (2009), é concomitante com a criação de um paradigma político para a educação, uma vez que os Estadosmembros constroem em paralelo políticas nacionais divergentes, através de uma coordenação da UE, para a obtenção de resultados convergentes.

Os fracos resultados atingidos pelos Estados-membros, em 2004, estão na origem de uma "obsessão" da União Europeia pela importância do investimento nos recursos humanos, que se prolonga e agudiza, até 2010 .

É também em 2004, que o processo de Copenhaga atinge a sua maturidade, com a educação, a formação profissional e o desenvolvimento de competências a ganharem maior força nos discursos da União Europeia, advogando uma maior articulação entre os sistemas educativos e o mercado de trabalho. Para o efeito, a Comissão das Comunidades Europeias expressa a necessidade de se incluírem novos indicadores no programa Educação e Formação 2010, relativos à formação profissional, de modo a permitir uma melhor comparabilidade e qualidade no âmbito da aprendizagem ao longo da vida. 
A partir de 2004, dados os poucos avanços dos Estados-membros, a União Europeia adota uma abordagem mais agressiva, enfatizando a urgência imperativa de reformas. Assim, constrói um conjunto de técnicas de vigilância e controlo, fortalecendo os processos de regulação transnacional e, consequentemente, o processo de europeizaçáo. Assim, define que os Estadosmembros são obrigados a cumprir as seguintes "orientaçóes integradas": preparar planos nacionais de reforma, a serem apresentados até final de 2005; nomear um coordenador nacional; apresentar um relatório anual de progressos nacionais; e seguir o programa comunitário definido pela Comissáo, para a convergência de políticas (CONSELHO EUROPEU, 2005).

Para Portugal essas recomendaçóes resultaram na criação do Programa Nacional de Ação para o Crescimento e o Emprego, para o período entre 20052008, servindo de "[...] guia para a concretizaçấo duma estratégia nacional de reformas e modernização concebida no quadro das referências e prioridades da Estratégia de Lisboa" (PNACE, 2006, p. 1). As recomendaçôes da UE para os Estados-membros, especificamente para Portugal, resultam, a partir de 2005, em orientaçóes mais direcionadas e específicas. Este programa assenta em dois vetores de intervençấo, um ligado à superação de constrangimentos à competitividade e atratividade do país, combatendo as carências de qualificaçôes e competências, e outro que acentua a necessidade de atrair investimentos privados para a concretização económica do país.

O Programa Novas Oportunidades enquadra-se no domínio da Qualificação, Emprego e Coesão Social, e é legitimado pelas exigências da sociedade do conhecimento, pela urgência da qualificação dos recursos humanos e pela promoção de emprego, sendo integrado no Plano Tecnológico e no Plano Nacional de Emprego. A situação do país em matéria de qualificação é caraterizada pela existência de grandes estrangulamentos estruturais:

Baixo nível de escolarização e qualificação profissional da população portuguesa, com implicaçóes fortemente negativas quer em termos de exclusão e coesão social, quer no avançar para a sociedade do conhecimento e da inovação, quer ainda em termos de aumento da produtividade do trabalho, que reflecte não só a baixa qualificação da população empregada (incluindo empresários e dirigentes de muitas micro e pequenas empresas) e formas pouco inovadoras na organização do trabalho [...]. (PNACE, 2006. p. 32). 
As pressōes provenientes de estudos comparativos e os resultados reduzidos que Portugal apresenta relativamente aos seus vizinhos europeus, "naturalmente tiveram um impacto no diagnóstico da situação do país, assim como na definição das políticas de educação e formação em Portugal" (EUROPEAN COMMISSION, 2005, p. 4). Nesse contexto, o PNACE define como grandes objetivos o reforço da educaçáo e qualificação dos portugueses e a promoção e criaçâo de emprego. À semelhança da racionalidade tecnocrática utilizada pela Uniẫo Europeia na Estratégia de Lisboa, também Portugal adota esta racionalidade, transformando os seus objectivos em metas quantitativas assentes na procura de resultados.

A influência dos objetivos e prioridades definidas pela União Europeia é claramente notória na criação e implementação do Programa Novas Oportunidades, sendo este devedor de um relançamento da Estratégia de Lisboa e de uma regulação transnacional mais forte e direcionada. O Programa Novas Oportunidades é, em nosso entender, o resultado desse fortalecimento, na medida em que é estruturado a partir de uma massificação de ofertas já existentes (Cursos de Educação e Formação de Adultos; Cursos CientíficoHumanísticos; Cursos Tecnológicos; Cursos Artísticos; Cursos Profissionais; Cursos de Educação e Formação e Processo de Reconhecimento, Validação e Certificação de Competências).

\section{5-2010: A instrumentalização da formação profissional europeia e a legitimidade do Programa Novas Oportunidades para a construção da Reforma da Formação Profissional em Portugal}

Com o novo ciclo de reformas europeias assiste-se a uma passagem de um ideal de coordenaçâo latente, para uma coordenação explícita, com base na criação de uma estrutura de aprendizagem ao longo da vida, onde a Formação Profissional se apresenta como uma poderosa ferramenta para dotar os cidadãos europeus de competências e qualificaçóes, quer através de dispositivos de formação inicial e reconhecimento de adquiridos para adultos pouco qualificados, quer de dispositivos de formação contínua em centros de aprendizagem e empresas, recorrendo aos fundamentos da Teoria do Capital Humano.

O progressivo enfoque na construção de um espaço da formação profissional, e não somente de educação, é levado a cabo pela integração das 
diretrizes do Processo de Copenhaga, expressão máxima do fortalecimento do processo de europeização até 2010, dada a ênfase na criação do Espaço Europeu da Formação Profissional, para uma articulação entre educação e formação profissional. A centralidade que a formação profissional assume nesse novo período é patente nas alteraçôes realizadas no Programa Educação e Formação 2010, quer a nível dos indicadores, quer a nível das designaçôes adotadas, que servem como um claro exemplo de uma governaçáo supranacional mais explícita e direcionada.

Essa viragem é assinalada por uma necessidade em se " [...] desenvolver um quadro coerente de indicadores e de marcas de referências para acompanhar o desempenho e o progresso no domínio da educação e formação" (CONSELHO EUROPEU, 2005, p. 7), que resulta, em 25 de maio de 2007, na aprovação de 20 novos indicadores, onde se assiste a uma passagem de 13 objetivos estratégicos para 8 grandes políticas chave.

A utilização de políticas chave oferece claras evidências do fortalecimento da governação supranacional. Não se trata de oferecer linhas de orientação (guidelines) para a concretização de marcas de referência, mas enfatizar a ação política em domínios específicos e concretos. Por sua vez, a diminuição do número de indicadores, que passam a ser 20 , expressa também uma centralização das prioridades das políticas nacionais a desenvolver pelos Estados-membros. Tendo em conta o nosso objeto de estudo apresentam-se no Quadro 2 as alteraçóes introduzidas.

A alteração mais significativa reside no desenvolvimento de um novo indicador que pretende contabilizar a percentagem de jovens que terminam o ensino secundário através de vias profissionalizantes. Essa introdução expressa, efetivamente, a inclusão do Processo de Copenhaga no programa, numa clara aposta no desenvolvimento de competências para o mercado de trabalho e promoção da empregabilidade. A inclusão desse novo indicador está também associada ao combate ao abandono escolar, uma vez que, "é evidente que os países com elevados níveis de participação no ensino profissional no ensino secundário têm geralmente níveis mais baixos de abandono escolar precoce" (EUROPEAN COMMISSION, 2008, p. 129). 
Quadro 2 - Marcas de referência, domínios políticos chave e indicadores do Programa Educação e Formação 2010 que estão associados ao Programa Novas Oportunidades

\begin{tabular}{|c|c|c|c|}
\hline & \multirow{2}{*}{$\begin{array}{l}\text { Marcas de } \\
\text { Referência }\end{array}$} & \multicolumn{2}{|c|}{$\begin{array}{l}\text { Domínios Políticos e Indicadores do } \\
\text { Programa Educação e Formação } 2010\end{array}$} \\
\hline & & $\begin{array}{l}\text { Domínios } \\
\text { Políticos Chave }\end{array}$ & Indicadores \\
\hline \multirow{3}{*}{ Jovens } & $\begin{array}{l}\text { Até } 2010, \text { pelo } \\
\text { menos } 85 \% \text { de } \\
\text { pessoas com } \\
22 \text { anos de } \\
\text { idade devem } \\
\text { ter completo } \\
\text { o Ensino } \\
\text { Secundário na } \\
\text { União Europeia }\end{array}$ & $\begin{array}{l}\text { Domínio } 3 \\
\text { Fazer da } \\
\text { aprendizagem } \\
\text { ao longo da vida } \\
\text { uma realidade } \\
\text { concreta }\end{array}$ & $\begin{array}{l}\text { Indicador } n^{\circ} 9-\text { Taxas } \\
\text { de conclusão do ensino } \\
\text { secundário por jovens } \\
\text { - Percentagem de } \\
\text { pessoas com } 22 \text { anos que } \\
\text { completaram pelo menos o } \\
\text { Ensino Secundário }\end{array}$ \\
\hline & \multirow{2}{*}{$\begin{array}{l}\text { Até } 2010 \text {, deve } \\
\text { ser alcançada } \\
\text { uma taxa média } \\
\text { europeia não } \\
\text { superior a } 10 \% \\
\text { de abandono } \\
\text { escolar precoce }\end{array}$} & $\begin{array}{l}\text { Domínio } 6 \\
\text { Modernizar } \\
\text { o ensino e } \\
\text { a formação } \\
\text { profissional } \\
\text { (Processo de } \\
\text { Copenhaga) }\end{array}$ & $\begin{array}{l}\text { Indicador } n^{\circ} 13- \\
\text { Estratificação dos sistemas } \\
\text { e ensino } \\
\text { - Percentagem de jovens } \\
\text { que terminaram o ensino } \\
\text { secundário por vias } \\
\text { profissionalizantes }\end{array}$ \\
\hline & & $\begin{array}{l}\text { Domínio } 1 \\
\text { Melhorar a } \\
\text { equidade na } \\
\text { educação e } \\
\text { formação }\end{array}$ & $\begin{array}{l}\text { Indicador } n^{\circ} 3 \text { - Abandono } \\
\text { Escolar Precoce } \\
\text { - Percentagem da } \\
\text { população entre os } 18 \text { e } \\
24 \text { com o Ensino Básico e } \\
\text { que não se encontram nos } \\
\text { sistemas de educação e } \\
\text { formação }\end{array}$ \\
\hline \multirow[t]{2}{*}{ Adultos } & \multirow{2}{*}{$\begin{array}{l}\text { Até } 2010, \\
\text { o nível de } \\
\text { participação em } \\
\text { aprendizagem } \\
\text { ao longo da } \\
\text { vida deve ser } \\
\text { pelo menos } \\
\text { de } 12,5 \% \text { na } \\
\text { população } \\
\text { adulta ativa } \\
\text { (grupo etário } \\
25-64 \text { ) }\end{array}$} & \multirow[t]{2}{*}{$\begin{array}{l}\text { Domínio } 3 \\
\text { Fazer da } \\
\text { Aprendizagem ao } \\
\text { Longo da Vida } \\
\text { uma realidade } \\
\text { concreta }\end{array}$} & $\begin{array}{l}\text { Indicador } n^{\circ} 16- \\
\text { Participação dos adultos na } \\
\text { educação e formação } \\
\text { - Percentagem da } \\
\text { população entre } 25-64 \\
\text { anos com menos do que } \\
\text { o ensino secundário, que } \\
\text { participaram em educação } \\
\text { e formação, nas } 4 \text { semanas } \\
\text { anteriores ao questionário. }\end{array}$ \\
\hline & & & $\begin{array}{l}\text { Indicador } \mathrm{n}^{\circ} 17- \\
\text { Competências dos Adultos } \\
\text { - Analisar as competências } \\
\text { digitais dos adultos. }\end{array}$ \\
\hline
\end{tabular}

Fonte: Criado a partir de COMMISSION OF THE EUROPEAN COMMUNITIES, 2008. 
Em 2008, com o Comunicado de Bordéus, a União Europeia acentua a necessidade de priorizar os adultos com baixos níveis de qualificação e o combate ao insucesso e abandono escolar, dado os reduzidos avanços de alguns Estadosmembros, assim como, a construção de instrumentos de formação profissional, com vista à modernização do mercado de trabalho europeu. A instrumentalização da formação profissional é notória, a partir do enfoque na construçáo de dispositivos de reconhecimento, validação e certificação de competências, do Europass, de um Quadro Europeu de Qualificaçôes, de um Sistema Europeu de Créditos e de um Sistema de Garantia para a Qualidade na Educação e Formação.

O ano de 2009 é destinado à avaliação dos progressos dos Estadosmembros, na elaboração de recomendaçóes e na deliberação de novas marcas de referência a atingir até 2020, integradas no Quadro Estratégico para a Educação e Formação 2020, onde a formação profissional desempenha um duplo papel: ajudar a responder às necessidades imediatas e futuras da Europa em matéria de competências e, ao mesmo tempo, reduzir o impacto social da crise e facilitar a recuperação (EUROPEAN COMMISSION, 2010). Para a década seguinte, a Comissão propóe utilizar o MAC como instrumento privilegiado de monitorizaçáo, baseado numa "estrutura de forte governaçáo que utiliza os instrumentos à sua disposição para garantir atempada e efetiva implementaçáo" e uma "vigilância mais próxima aos países" (EUROPEAN COMMISSION, 2010, p. 25), o que no nosso entender, poderá pôr em causa o princípio de subsidiaridade, redefinindo-o.

Para Portugal, a maturação do Processo de Copenhaga e a instrumentalização da formação profissional para a criação do mercado europeu de educação, resulta na criação, em 2006, da Agência Nacional para a Qualificação (atual Agência Nacional para a Qualificaçáo e Ensino Profissional), destinada à regulação e coordenaçáo das políticas de educação e formação, enquadradas no PNO. Por sua vez, em novembro de 2007 é publicada a Resolução do Conselho de Ministros no 173/2007, que aprova um conjunto de medidas para a Formação Profissional, que só têm expressão quando enquadradas num contexto europeu, nomeadamente: a estruturaçáo da oferta relevante certificada através do Catálogo Nacional de Qualificaçóes, a reforma das instituiçóes e a regulaçáo da formação, através do Sistema Nacional de Qualificaçóes e a reforma do sistema de acreditação e qualidade.

Essa Reforma da Formação Profissional é corolário das recomendações da Comissão Europeia, em 2006, aquando da avaliação do primeiro ano de execução do Programa Nacional de Ação para o Crescimento e o Emprego, cujas orientaçóes procuravam "implementar medidas para melhorar fortemente os 
níveis de conclusão da educação dos jovens, e desenvolver um sistema de formação profissional relevante para as necessidades no mercado de trabalho baseado no Quadro Nacional de Qualificaçôes” (EUROPEAN COMMISSION, 2006).

Em 2008, é lançado um novo plano de reformas, Plano Nacional de Reformas (2008-2010), cuja racionalidade e orientaçóes se mantêm, incidindo na importância do investimento para a educaçáo e formação. As metas definidas para o caso português também não foram atingidas, à excepção do número de Centros Novas Oportunidades em funcionamento e o estabelecimento $12^{\circ}$ ano como referencial de mínimo de formação para todos, com a Lei no 85/2009, de 27 de agosto de 2009.

Para reforçar a nossa argumentação, apresentamos a evolução dos indicadores em paralelo para o abandono escolar precoce (gráfico 1) e conclusão do ensino secundário (gráfico 2).

Gráfico 1- Indicador n⿳32/3 - Abandono escolar precoce

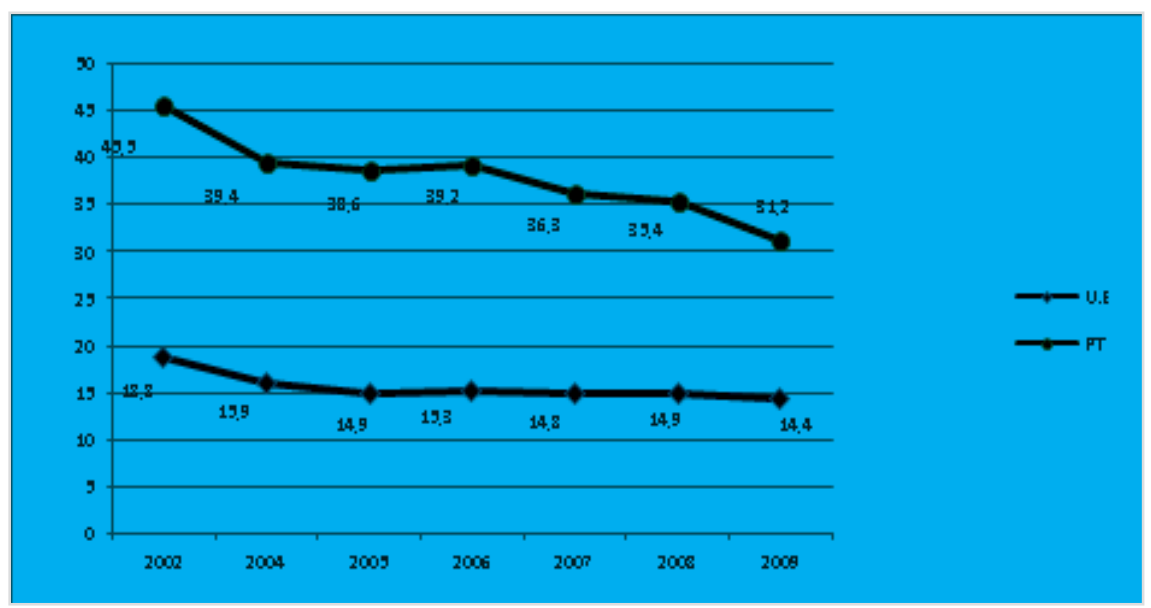

Fonte: Elaborado a partir dos Relatórios de Progresso para o Programa Educação e Formação 2010 (COMMISSION..., 2005; 2006; 2007; 2008, 2009 e 2010).

Entre 2002 e 2009, assiste-se em Portugal a uma Reforma do Ensino Secundário que resulta numa tentativa de combater o insucesso e abandono escolar através de uma diversificação da oferta de vias profissionalizantes. Através de uma forte ênfase discursiva numa aliança entre as políticas de educação e formação (PORTUGAL, 2003), é reestruturada a oferta do ensino secundário, com uma forte incidência nas ofertas de cariz profissionalizante cursos tecnológicos, cursos artísticos, cursos profissionais e cursos de educação e 
formação. A diferença de 14,3 pontos percentuais referente ao abandono escolar ente 2002 e 2009 (Gráfico 1) deve-se, exatamente, à expansão da oferta do ensino secundário que veio permitir a diversificação dos percursos individuais para a conclusão do ensino secundário, em linha com as orientações discursivas e estratégicas da União Europeia.

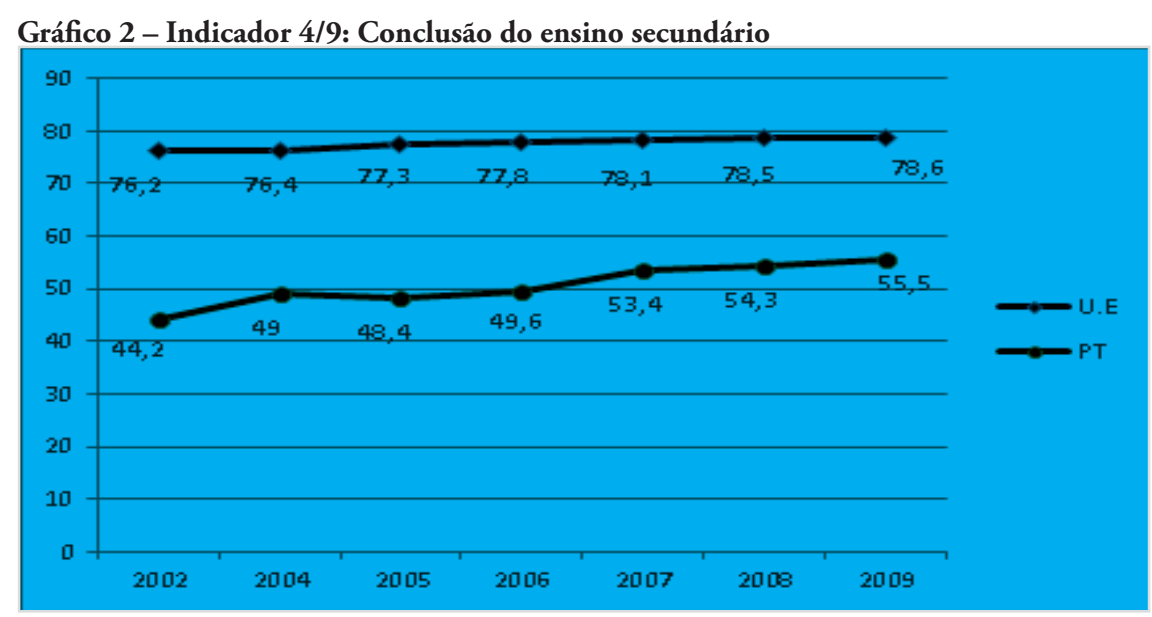

Fonte: Elaborado a partir dos Relatórios de Progresso para o Programa Educação e Formação 2010 (Commission..., 2005; 2006; 2007; 2008, 2009 e 2010).

Num contexto em que o aumento da oferta pública de nível secundário é acompanhado por um aumento da procura individual não é de se estranhar que a taxa de conclusão do Ensino Secundário (Gráfico 2) passe de 44,2\% em 2002 para $55,5 \%$ em 2009.

A partir de 2005, com mais expressão em 2007, assiste-se a uma diminuiçáo substancial do abandono escolar e a um aumento da conclusão do ensino secundário, devedores da expansão e diversificação da oferta das vias profissionalizantes, sob a égide do Programa Novas Oportunidades. Essa correlação é claramente notória se atentarmos na percentagem de alunos que terminaram em 2006 o ensino secundário por vias profissionalizantes. No total de $49,2 \%$ de alunos, 31,5\% terminaram através do ensino profissional, tendência que se mantém até aos últimos dados, referentes a 2008, apresentando um valor de 34,4\% (COMMISSION..., 2007; 2009).

A estratégia da Uniāo Europeia, apropriada pelo Estado português para a diminuiçáo do abandono escolar e da conclusão do ensino secundário, pode 
ser interpretada segundo o que Stoer, Stoleroffe Correia (1990), e Alves (2008) designam por vocacionalismo. Para os autores, o vocacionalismo promove a crença do papel fundamental que a educação desempenha para aumentar a competitividade das economias europeias e para a diminuição do desemprego. Esse relançamento da Teoria do Capital Humano na Estratégia de Lisboa é, para Alves (2008), uma expressão da impossibilidade ideológica de os Estadosmembros intervirem diretamente na economia, por via da criação de emprego, transferindo para os sistemas de educação e formação a responsabilidade de combater o desemprego. Associado a um problema económico, o triunfo do vocacionalismo como marco incontornável para a reduçáo do abandono e insucesso escolar pretende se constituir como

[...] uma oferta suficientemente atraente para um número elevado de jovens, permitindo-lhes fazer face à desvalorizaçáo dos diplomas; ao manter durante mais tempo um maior número de jovens na escola, a educação profissionalizante contribui para diminuir as taxas de desemprego juvenil. (ALVES, 2008, p. 15).

No que diz respeito aos adultos pouco escolarizados, a evolução do indicador relativo à participação de adultos na educação e formação (Gráfico 3), também oferece uma clara visão do impacto do Programa Novas Oportunidades, uma vez que de 2006 a 2008 assinala um aumento de 14,6\%.

O contributo do Programa Novas Oportunidades para o exponencial aumento deste indicador é visível se atentarmos ao nascimento do Processo Reconhecimento, Validação e Certificação de Competências e dos cursos de Educação e Formação de Adultos em 2000, que só tiveram um real impacto, a partir de 2007, devido à expansão da rede de Centros Novas Oportunidades e de uma estratégia discursiva em torno da importância da qualificação para o desenvolvimento económico e para os retornos individuais do investimento na aprendizagem. Entre o ano letivo de 2006/2007 até ao ano letivo de 2009/2010, ano de atuaçáo do Programa Novas Oportunidades, cerca de 239 mil adultos obtiveram uma dupla certificação através dos Cursos de Educação e Formação para Adultos, e cerca de 400 mil, viram validadas e certificadas as suas competências através do processo de Reconhecimento, Validaçáo e Certificação de Competências (PORTUGAL, 2011). 
Gráfico 3 - Indicador $n^{\circ}$ 19/16: Participação de adultos na educação e formação. Percentagem da população entre 25-64 anos com menos do que o Ensino Secundário que participaram em educação e formação, nas 4 semanas anteriores ao questionário

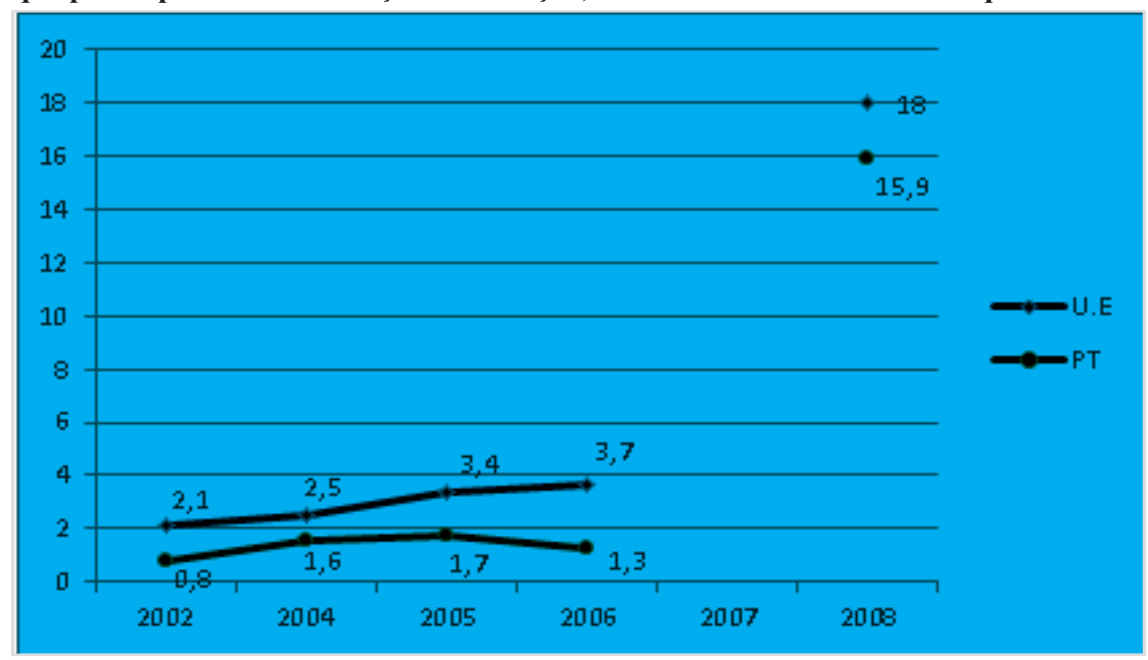

Fonte: Elaborado a partir dos Relatórios de Progresso para o Programa Educação e Formação 2010 (Commission..., 2005; 2006; 2007; 2008, 2009 e 2010).

\section{Considerações Finais}

A ação da União Europeia deve ser entendida segundo dois momentos distintos. No primeiro, entre 2000 e 2005 , a açáo é pautada por uma crescente articulação que culmina na integração dos objetivos do Processo de Copenhaga no Programa de Educaçáo e Formaçáo 2010, passando de um ideal de coordenaçấo latente, para um de coordenaçáo efetivo. A própria passagem de designações e o enfoque na construção de um Espaço Europeu da Formação Profissional, ao invés de Educaçáo, menos expressivo a partir de 2005, coloca o vocacionalismo no centro nevrálgico de atuação para a construção de políticas para jovens e adultos pouco escolarizados.

Em nosso entender, o PNO enquadra-se numa política de oportunidade (CAVACO, 2009), dado que se centra e procura efeitos imediatos, associados a uma lógica de rentabilidade económica e numa lógica da qualificação de recursos humanos, onde os processos de aprendizagem individuais se apresentam neutros e despolitizados (LIMA, 2005). Na realidade, o PNO encerra em si, um conjunto de ideologias (MARQUES, 2010) na expressão 
Aprender Compensa, próprias do projeto neoliberal, na forma como entende a função da educação. Natália Alves (2009, p. 55) é particularmente clara neste ponto, ao afirmar que se assiste a uma lógica de responsabilização individual "[...] para tornar os actores nos únicos responsáveis pelas suas trajetórias individuais e nos únicos responsáveis pelos seus sucessos e fracassos, numa escalada crescente de privatização dos problemas sociais e de culpabilização das vítimas".

Apesar da criação do PNO ser concomitante com a regulação mais forte e direcionada da União Europeia para o cumprimento de metas, a nossa análise, carece ainda de conhecimento aprofundado quanto ao nível de influência dos processos de regulação transnacional para a construção de políticas públicas a nível nacional. Pese embora os limites da nossa análise, confirmamos, a partir dos dados, que o PNO veio responder, em grande medida, aos desígnios europeus, apropriando-se e reproduzindo os discursos da Uniáo Europeia. Ele adota a mesma racionalidade tecnocrática e estratégica quanto aos resultados, bem como quanto à centralidade que o vocacionalismo assume, contribuindo para a construção de uma agenda globalmente estruturada para a educação.

\section{Notas}

${ }^{1}$ As marcas de referência foram lançadas em 2002, no entanto, redefinidas devido à articulação com os indicadores do Programa Educação e Formação 2010. Segundo a Comissão das Comunidades Europeias (2002, p. 7), o termo "[...] marcas de referência é utilizado com referência a objectivos concretos com base nos quais é possível medir os progressos realizados". Quanto aos indicadores do programa, assistiu-se em 2003 a uma reestruturação do programa onde foram incluídos 29 indicadores, de modo a recomendar os Estados-membros na fabricação de açôes mais concretas e direcionadas. Segundo a Comissão das Comunidades Europeias (2003, p. 99), "isto levou a uma lista preliminar de 29 indicadores relevantes e tornou possível identificar as áreas que requeriam novos desenvolvimentos. A adoção pelo Conselho de Educação a 5 de Maio de 2003 de 5 novos níveis comuns de referência (marcas de referência) é um passo adicional para a atual implementação do método aberto de coordenação na educação e formação". 
${ }^{2}$ Segundo a Comissão Europeia o Processo de Copenhaga procura a melhoria do desempenho, a qualidade e a atratividade do ensino e da formação profissionais a nível europeu. Através de prioridades mutuamente acordadas, o Processo de Copenhaga tem em vista uma cooperação reforçada, apresentando como objetivos: reforçar a dimensão europeia do ensino e da formação profissionais; aumentar a informaçáo, orientação e aconselhamento, bem como a transparência, do ensino e da formação profissionais; criar ferramentas para o reconhecimento mútuo e a validação de competências e qualificaçóes; e melhorar a garantia de qualidade do ensino e da formação profissionais. Iniciado em 2002, em Copenhaga, foi revisto em 2004, em Maastricht, em 2006, em Helsínquia, em 2008, em Bordéus, e em 2010, em Bruges.

\section{REFERÊNCIAS}

ALTHEIDE, David et al. Emergent qualitative document analysis. In: HESSE-BIBER, Sharlene N.; LEAVY, Patricia (Ed.). Handbook of emergent methods. New York: The Guilford Press, 2008. p. 127-149.

ALVES, Natália. Políticas de educação-formação para jovens: tensões e contradiçôes. Perspectiva, Florianópolis, SC, v. 26, n. 1, p. 209-230, jan./jun. 2008.

ALVES, Natália. Por que está a escola incumbida de promover a inclusão e empregabilidade? In: CANÁRIO, Rui, RUMMERT, Sonia. (Org.). Mundos do Trabalho e Aprendizagem. Lisboa: Educa, 2009. p. 45-59.

BARROSO, João. A investigação sobre a regulação das políticas públicas de educação em Portugal. In: BARROSO, João. (Org.). A regulação das politicas públicas da educação: espaços, dinâmicas e actores. Lisboa: Educa, 2006a. p. 9-34.

BARROSO, João. O Estado e a Educaçáo: a regulação transnacional, a regulação nacional e a regulação local. In: BARROSO, João. (Org.). $A$ regulação das políticas públicas da educação: espaços, dinâmicas e actores. Lisboa: Educa, 2006b. p. 41-67.

BERNSTEIN, Basil. Pedagogy, symbolic control and identity: theory, research, critique. London: Taylor and Francis, 1996.

BÜCHS, Milena. How legitimate is the open method of co-ordination? Journal of Common Market Studies, New Jersey, v. 46, n. 4, p. 765-786, 2008. 
CAVACO, Carmen. Adultos pouco escolarizados: políticas e práticas de formação. Lisboa: Educa; UI\&DCE, 2009.

COMMISSION OF THE EUROPEAN COMMUNITIES. Commission staff working paper. Implementation of the "Education \& Training 2010" programme: Supporting document for the draft joint interim report on the implementation of the detailed work programme on the follow-up of the objectives of education and training systems in Europe. Brussels, 11 nov. 2003. Sec (2003) 1250. Disponível em: <http://bit.ly/s9iPeL>. Acesso em: 3 fev. 2009.

COMMISSION OF THE EUROPEAN COMMUNITIES. Commission staff working paper. Progress towards the Lisbon objectives in education and training: indicators and benchmarks 2005. Brussels, 22 mar. 2005. Sec (2005) 419. Disponível em: <http://bit.ly/Hjv4BO>. Acesso em: 3 fev. 2009.

COMMISSION OF THE EUROPEAN COMMUNITIES. Commission staff working paper. Progress towards the Lisbon objectives in education and training: Indicators and Benchmarks 2006. Brussels, 16 mayo 2006. Sec (2006) 639. Disponível em: <http://goo.gl/6vO7g>. Acesso em: 15 fev. 2009.

COMMISSION OF THE EUROPEAN COMMUNITIES. Commission staff working paper. Progress towards the Lisbon objectives in education and training. indicators and benchmarks 2007. Brussels, 2007. Sec (2007)1284. Disponível em: <http://bit.ly/8X1QMw>. Acesso em: 15 fev. 2009.

COMMISSION OF THE EUROPEAN COMMUNITIES. Commission staff working paper. Progress towards the Lisbon objectives in education and training: indicators and benchmarks 2008. Brussels, 2008. Sec (2008) 2293. Disponível em: <http://goo.gl/V6BZG>. Acesso em: 15 fev. 2009.

COMMISSION OF THE EUROPEAN COMMUNITIES. Commission staff working paper. Progress towards the Lisbon objectives in education and training. Indicators and Benchmarks 2009. Brussels, 2009. Sec (2009)1616. Disponível em: <http://goo.gl/zL1A7>. Acesso em: 10 abr. 2010.

COMMISSION OF THE EUROPEAN COMMUNITIES. Commission staff working paper. Progress towards the Lisbon objectives in education and training: indicators and benchmarks 2010/2011. Brussels, 2011. Sec (2011)526. Disponível em: <http://bit.ly/eVi8HY>. Acesso em: 23 nov. 2011. 
CONSELHO EUROPEU. Conclusóes da Presidência: Conselho Europeu de Lisboa de 23 e 24 de Março. Lisboa, 2000. Disponível em: <http://goo.gl/ Rjywp>. Acesso em: 25 out. 2009.

CONSELHO EUROPEU. Conclusōes da Presidência: Conselho Europeu de Bruxelas de 22 e 23 de Março. Bruxelas, 23 mar. 2005. Disponível em: $<$ http://goo.gl/0HlYD>. Acesso em: 26 out. 2009.

DALE, Roger. Specifying globalization effects on national policy: a focus on the mechanisms. Journal of Education Policy, New York, v. 14, n. 1, p. 1-17, 1999.

DALE, Roger. Globalização e educação: demonstrando a existência de uma "cultura educacional mundial comum" ou localizando uma "agenda globalmente estruturada para a educação"? Educação, Sociedade e Culturas, Porto, v. 16, p. 133-169, 2001.

DALE, Roger. Globalización: un nuevo mundo para la educación comparada? In: SCHRIEWER, Jürgen. (Ed.). Formación del discurso en la educación comparada. Barcelona: Pomares, 2002. p. 69-90.

DALE, Roger. A Globalização e a reavaliação da Governação Educacional: um caso de ectopia sociológica. In: TEODORO, António; TORRES, Carlos A. (Org.). Educação Crítica e Utopia: perspectivas para o século XXI. Porto: Afrontamento, 2005. p. 53-69.

DALE, Roger; ROBERTSON, Susan, L. The varying effects of regional organizations as subjects of globalization of education. Comparative Education Review, Chicago, v. 46, n. 1. p. 10-36, 2002.

DALE, Roger; ROBERTSON, Susan, L. New arenas of global governance and international organisations: reflections and directions. Centre for Globalisations, Education and Societies, Bristol, p. 1-10, 2007. Disponível em: $<$ http://goo.gl/I9Q5D >. Acesso em: 12 mar. 2009.

EUROPEAN COMMISSION. Implementing the education and training 2010, work programme: progress report portugal. Brussels, dec. 2005. Disponível em: <http://goo.gl/WuxEJ>. Acesso em: 14 jan. 2010.

EUROPEAN COMMISION. Assessment of national reform programmes: Portugal. Brussels, 2006. Disponível em: <http://bit.ly/s2efMe>. Acesso em: 14 jan. 2010.

EUROPEAN COMMISSION. Europe 2020: a European strategy for smart, sustainable and inclusive growth. Brussels, 3 mar. 2010. Disponível em: <http://goo.gl/jZhjN>. Acesso em: 10 jun. 2010. 
FAIRCLOUGH, Norman. Critical discourse analysis: papers in the critical study of language. England: Pearson Education Limited, 1995.

LIMA, Licínio. A educação de adultos em Portugal (1974-2004): entre as lógicas da educação popular e da gestão dos recursos humanos. In: CANÁRIO, Rui; CABRITO, Belmiro (Org.). Educação e formação de adultos: mutações e convergências. Lisboa: Educa, 2005. p. 31-60.

MARQUES, Marcelo. Entre Bruxelas e Lisboa: a europeização das políticas educativas no Programa Novas Oportunidades. Lisboa: Universidade de Lisboa, 2010. Disponível em: <http://bit.ly/s27IrW>.

PORTUGAL. Ministério da Educação. Reforma do Ensino Secundário: documento orientador da reforma curricular. Lisboa, 10 apr. 2003. Disponível em: <http://bit.ly/shybEI>. Acesso em: 4 jun. 2010.

PORTUGAL. Ministério da Educação. Estatísticas da educação 2009/2010 - adultos. Lisboa: Gabinete de estatística e planeamento da educação, 2010. Disponível em: <http://bit.ly/hrrrdz>. Acesso em: 10 jan. 2011.

PNACE. Programa Nacional de Acção para o Crescimento e Emprego. Estratégia de Lisboa: Portugal de Novo, 2005-2008. Lisboa, out. 2006. Disponível em: <http://bit.ly/sjQiVO>. Acesso em: 18 mayo 2010.

RADAELLI, Claudio M. The europeanization of public policy. In: FEATHERSTONE, Kevin; RADAELLI, Claudio (Ed.). The Politics of Europeanization. Oxford: University Press, 2003. p. 27-56.

SÓCRATES, José. A ambição. In: SÓCRATES, José. Novas Oportunidades: aprender compensa. Lisboa, 2005.

STOER, Stephen, R.; STOLEROFF, Alan; CORREIA, José, A. O Novo Vocacionalismo na política educativa em Portugal e a reconstrução da lógica de acumulação. Revista Crítica das Ciências Sociais, Coimbra, v. 29, p. 11-53, 1990. 


\section{Le Programme Nouvelles Opportunités: dans une agenda globalement structurée pour l'éducation}

\section{Résumé}

Cet article présent une analyse critique de la création et de la mise en ouvre de la mesure de politique éducative la plus emblématique pour le domaine de la jeunesse et des adultes peu scolarisés au Portugal: le Programme Nouvelles Chances. D'après la proposition théorique de Roger Dale sur l'éducation structurée au niveau mondial, nous discutons la fabrication de cette mesure à partir d'un scénario de régulation transnationale. Grâce à une analyse documentaire d'une série de documents européens et nationaux entre la période 2000 et 2010 dans le domaine de l'éducation des jeunes et des adultes, on a vérifié que le Programme est le résultat d'un renforcement du processus de régulation des politiques éducatives, menée par l'Union européenne. Ce renforcement a permis la construction d'un programme politique pour le domaine de l'éducation des jeunes et des adultes au Portugal qui partage soit les mêmes idéologies instrumentales répandues par l'Union européenne, soit une gestion technocratique des politiques éducatives, sur la base de la demande des résultats.

Mots-clés: Milieu Politique. Politique mondiale de l'éducation. Éducation des Jeunes et des Adultes.

\section{The New Opportunities Program in a globally structured agenda for education}

\section{Abstract}

This article presents a critical analysis of the creation and implementation of the most emblematic political measure for the field of youth and adults with little schooling in Portugal: New Opportunities Program. Based on Roger Dale's proposal about the global structured agenda on education. We discussed the fabrication of this measure from a scenario of transnational regulation. Through document analysis of a set of European and national documents produced between the period 2000 and 2010, it was found that the New Opportunities Program is a result of a strengthening of the process of educational policies regulation, carried out by the European Union. This strengthening resulted in the construction of a political program for the field of youth and adult education in Portugal which shares both the same instrumental ideologies spread by the European Union, and a technocratic administration of educational policies, based on the search for results

Keywords: Political context. Worldwide education policy. Young and Adults Education. 


\section{Marcelo Marques}

E-mail: marquescmarcelo@gmail.com

\section{Natália Alves}

E-mail: nalves@ie.ul.pt

Recebido em: 28/3/2013

Ultima versáo recebida $\mathrm{em:}$ : 25/5/2013

Aprovado em: 29/5/2013 